\title{
SCIDiC
}

\author{
International Journal of Dentistry and Oral Science (IJDOS) \\ ISSN: 2377-8075
}

\section{Synthesis and Characterisation Of Novel Turmeric Gold Nanoparticles and Evaluation Of Its Antioxidant, Anti-Inflammatory, Antibacterial Activity For Application In Oral Mucositis-An Invitro Study}

Research Article

Sreedevi Dharman ${ }^{1 *}$, Rajesh Kumar $^{2}$, Karpagavalli Shanmugasundaram ${ }^{3}$

${ }^{1}$ Reader, Department of Oral Medicine \& Radiology, Saveetha Dental College and Hospitals, Saveetha Institute of Medical and Technical Sciences, Saveetha University, Chennai-60007, Tamil Nadu, India.

${ }^{2}$ Associate Professor, Nanobiomedicine Lab, Department of Pharmacology, Saveetha Dental College and Hospitals, Saveetha Institute of Medical and Technical Sciences Saveetha University, Chennai, Tamil Nadu, India.

${ }^{3}$ Professor \& Head, Department of Oral Medicine \& Radiology, Seema Dental College \& Hospitals, Rishikesh.

Abstract

Objective: This article aimed to green synthesize and characterize turmeric mediated gold nanoparticles (TuAuNP) and to evaluate its antioxidant, anti-inflammatory, antibacterial activity against oral pathogens for its application in oral mucositis. Materials and Method: Aqueous extract of turmeric powder were used to reduce, stabilize and capgold nanoparticle (AuNP). Reduction of Au3+ to Au NPs were initially observed by colour change from yellow solution to red violet colour within 15 minutes. TuAuNP were analytically characterised by UV-visible spectrophotometer (UV-Vis), Transmission Electron Microscopy (TEM), X-Ray Diffraction Assay (XRD), Fourier Transform Infra Red Analysis (FTIR) and evaluated its antioxidant, anti-inflammatory, antibacterial activity against oral pathogens.

Results: Surface Plasmon Resonance bandwith an absorption peak at around $540 \mathrm{~nm}$ preliminarily confirmed TuAuNP synthesis. TEM Analysis showed spherical shaped, smooth edged, size ranged of 5-15 nm. XRD analysis revealedface centered cubic crystallinity with intense sharp peaks at $38^{\circ}, 44^{\circ}, 64^{\circ}$ and $77^{\circ}$. FTIR showed peaks of the functional groups of different phytochemicals of the rhizome extract involved as reducing and capping agent. TuAuNp exhibited $83 \%$ highest scavenging ability of DPPH radical at concentration of $50 \mu \mathrm{g} / \mathrm{mL}$. TuAuNP showed $89.5 \%$ of maximum anti-inflammatory activity at $50 \mu \mathrm{g} / \mathrm{mL}$ than standard drug diclofenac. TuAuNP exhibited good antibacterial activity against Streptococcusmutans, Klebsiella Pneumoniae at $100 \mu \mathrm{g} / \mathrm{mL}$, Pseudomonasaeruginosa, Enterococcifaecalis at $50 \mu \mathrm{g} / \mathrm{mL}$, moderate antibacterial activity against Staphylococci aureus at $50 \mu \mathrm{g} / \mathrm{mL}$.

Conclusion: Turmeric mediated green synthesis of gold nanoparticles exhibited good antioxidant, anti-inflammatory, broad spectrumantibacterial activities against oral pathogens that could be applied in treating oral mucositisas oral insitu or transmucosal preparations.

Keywords: Turmeric Extract; Gold Nanoparticles; Antioxidant; Anti Inflammatory; Antibacterial; Oral Mucosal Lesions.

\section{Introduction}

Oral mucositis is the most common side effect of Chemo-radiotherapy in head and neck cancer patients. It is clinically character- ized by erythema, ulcerations with superadded infections of oral mucosa which could be painful and debilitating to patients. Till now there are no accepted method for prevention and treatment for oral mucositis [1]. Synthetic drugs may have beneficial thera-

\section{*Corresponding Author}

Sreedevi Dharman,

Reader, Department of Oral Medicine and Radiology, Saveetha Dental College and Hospitals, Saveetha Institute of Medical and Technical Sciences, No.162, Poonamalle High Road, Velappanchavadi, Chennai- 600077, Tamil Nadu, India.

Tel: 9841009003

Email Id: sanjamrut@gmail.com

Received: April 15, 2021

Accepted: May 10, 2021

Published: May 20, 2021

Citation: Sreedevi Dharman, Rajeshkumar, KarpagavalliShanmugasundaram. Synthesis and Characterisation Of Novel Turmeric Gold Nanoparticles and Evaluation Of Its Antioxidant, Anti-Inflammatory, Antibacterial Activity For Application In Oral Mucositis-An Invitro Study. Int J Dentistry Oral Sci. 2021;08(05):2525-2532.

doi: http://dx.doi.org/10.19070/2377-8075-21000495

Copyright: Sreedevi Dharman 2021 . This is an open-access article distributed under the terms of the Creative Commons Attribution License, which permits unrestricted use, distribution and reproduction in any medium, provided the original author and source are credited. 
peutic effects but are associated with adverseeffects [2].

Herbal drugs with beneficial properties, reduced side effects and faster healing capacityare warranted in present scenario. Turmeric is the rhizome of curcuma longa Linn belongs to ginger family widely utilized as an ingredient spice. It has anti-inflammatory, antiseptic, analgesic, wound healing property [3]. Curcumin is the important colouring compound of turmeric that is responsible for many features of it [4]. Adequate turmeric concentration are needed in target tissues for its pharmacological effects. Rapid absorption, poor bioavailability, rapid metabolism, excretion limits the beneficial action ofturmeric [5]. To solve these problems, nanoparticle-based drug delivery approaches are the right choice to enhance the wider medicinal applications of turmeric [6]. Nanoparticles are $1-100 \mathrm{~nm}$ in diameter that has the ability to penetrate cells, translocate to other cells, tissues, organs distant from portal of entry to the body [7].

Nanobiotechnology is a multidisciplinary research field that involves nanomaterials synthesis through physical, chemical and biological methods [8]. Toxic chemicals are used as reducing, capping and stabilization agents in physicochemical methods leading to non ecofriendly products [9]. Plant extract synthesized metal nanoparticles are simple and environmentally friendly materials [10]. Inorganic nanomaterials have versatile features like targeted drug delivery, controlled release of drug, good compatibility and bioavailability [11]. Nanometals like silver, gold, titanium, zinc, copper and zirconia are currently used in various biomedical applications. Among which gold nanoparticles (AuNPs) show distinctive properties like high surface area, tunable preparation, small size to volume ratio, thermalstability, low cytotoxicity. Due to these properties, AuNPs are applied in diagnostic and therapeutic functions [12].

In dentistry, they are used in prosthodontics, restorative dentistry, periodontology, dental implants, diagnosis and therapy of oral cancer. AuNPs with specific size could promote osteogenic differentiation that aid in periodontal regeneration [13]. AuNPs synthesized by green chemistry upregulate bone formation, down regulate bone resorption which is used as an active bone inductive material during dental implant treatment [14]. New denture base material modified with AuNp showed increased hardness, thermal conductivity, density with less flexural strength and elastic modulus [15]. AuNPs improved the mechanical properties of adhesive resins with no toxicity to cells [16]. AuNPs had better optical properties are used in early cancer diagnosis, passively accumulate at tumor sites are more promising than small drug molecules. Glutathione peroxidase modified ultrasmall AuNPs had enhanced permeability and retention effect and were further cleared from normal tissues soon after imaging [17]. AuNPs enhance the cytotoxic effect against cancer cells inducing cellular apoptosis in addition to its action as drug carriers [18].

In dentistry, application of AuNPs in treating oral mucosal lesions are sparse. Due to its drug carrier potential, they can enhance turmeric bioavailability which can help in treating oral mucositis. To the best of our knowledge, the antioxidant, anti-inflammatory, antibacterial activity against oral pathogens of turmeric mediated AuNps were not studied before, hence our present research aimed to develop original method of Turmeric mediated AuNps and evaluation of its antioxidant, anti-inflammatory, antibacterial activity against oral pathogens that can be used in translational research for treating oral mucositis.

\section{Methods}

Materials: “Turmeric, Gold chloride, DPPH (2,2-diphenyl-1- picrylhydrazyl), Ascorbic Acid, Bacterial media" were purchased from (Hi media, Mumbai,India).

\section{Turmeric Extract Preparation}

$1 \mathrm{gm}$ of turmeric was weighed and added with $100 \mathrm{ml}$ of distilled water. The mixture was boiled for 10 minutes and placed at room temperature. Turmeric extract was filtered using Whatman filter paper.

\section{Biosynthesis Of Gold Nanoparticle}

0.393 gram of gold (III) chloride trihydrate $\left(\mathrm{HAuCl}_{4} .3 \mathrm{H}_{2} \mathrm{O}\right)$ was added with $100 \mathrm{ml}$ of distilled water to produce stock solution. $10 \mathrm{ml}$ of turmeric extract and $10 \mathrm{ml}$ of $1 \mathrm{mM}$ aqueous chloroauric $\operatorname{acid}\left(\mathrm{HAuCl} 4.3 \mathrm{H}_{2} \mathrm{O}\right)$ was mixed in $80 \mathrm{ml}$ of distilled water and kept in orbital shaker overnight. Colour change was visually observed for every 1 hour when Au3+ were reduced and converted to $\mathrm{Au}^{0}$ indicating the TuAuNP formation.

\section{Purification and Characterisation Of Gold Nanoparticles}

Green synthesised TuAuNP were characterised by Ultraviolet (UV)-visible spectrophotometer (ELICO SL201 UV-V is spectrophotometer). Control solution was distilled water that served as a blank and nanoparticle solution were scanned simultaneously from 400-650 nm. UV-V is spectrophotometry confirm the reduction in metalions in to metal nanoparticles, which were monitored at different time intervals 1, 2, 6, $24 \mathrm{hr}$. After the complete reduction in metal salt to nanoparticles, they were further purified by centrifugation at $6,500 \mathrm{rpm}$ for $15 \mathrm{~min}$, supernatant discardedandthe nanoparticles were collected in the form of a pellet by air-drying at $70^{\circ}$ for $30 \mathrm{~min}$, which was used for analytical characterization.

\section{Transmission Electron Microscopy}

Transmission Electron Microscopy (TEM) (Make; PHILIPS Model; CM 200) provides a further insight into the morphology and size details of theTuAuNP. TEM images were obtained with high resolution megapixel camera at various magnification ranges. TuAuNP aqueous solution drop were deposited on carbon coated copper grid, excess solution were removed and was allowed to dry in oven at $60^{\circ}$.

\section{X-Ray Diffraction Assay}

Crystallinity of synthesized AuNPs were assessed by XRD (D8 Diffractometer, Bruker, Germany) with a step size of $0.02^{\circ}$, scanning speed of $4^{\circ} \mathrm{min}^{-1}$ working in $2 \theta$ range of $10-80^{\circ}$ at $40 \mathrm{KV}$ and $40 \mathrm{Ma}, \alpha$ radiation of $1.54 \mathrm{~A}^{\circ}$. AuNps average sizewere obtained by using Debye-Scherrerequation.

$\mathrm{D}=0.9 \lambda / \beta \operatorname{Cos} \theta$

Dis crystalline sizein $\mathrm{nm}, \lambda$ is wavelength of $\mathrm{X}$-ray $\left(1.5406 \mathrm{~A}^{\circ}\right), \beta$ 
is the full width at half maximum (FWHM) in radians, and $\theta$ is Braggs angle in radians [19].

\section{Fourier Transform Infra Red Analysis}

FTIR analysis were done using Nicolet spectrometer (Thermo scientific, Waltham, MA, USA) to identify functional groups attached to AuNPs which were reducing agents in nanoparticle synthesis. Aqueous solution were air dried and evaluated by 64 interferogram scan in the spectrum range of $400-4000 \mathrm{~cm}^{-1}$ at $1 \mathrm{~cm}^{-1}$ resolution.

\section{Antioxidant Activity}

Antioxidant activity of the TuAuNP were measured using DPPH (2,2-diphenyl-1- picrylhydrazyl) assay. $1 \mathrm{ml} \mathrm{DPPH}(80 \mu \mathrm{g} / \mathrm{mL})$ $0.2 \mathrm{~mm}$ solution in methanol $(0.1 \mathrm{~g} / \mathrm{L})$ and $1 \mathrm{ml}$ of TuAuNP with different concentration $(10 \mu \mathrm{L}, 20 \mu \mathrm{L}, 30 \mu \mathrm{L}, 40 \mu \mathrm{L}, 50 \mu \mathrm{L})$ of solutions were 30 minutes incubated at room temperature. Methanoliccoloured DPPH is reduced to non colouredsolution. Decrease in absorbance was measured in $517 \mathrm{~nm}$. Ascorbic acid was the standard solution.

-Absorbance of sample solution was used to calculate Inhibition Percentage:

(Absorbance of control-Absorbance of sample/ Absorbance of control) x100

Absorbance of control is absorbance of DPPH and methanol and Absorbance of sample is the absorbance of DPPH and sample extract.

\section{Antinflammatory Activity}

Anti-inflammatory activity was done by Albumin denaturation assay. $2 \mathrm{ml}$ of $1 \%$ aqueous Bovine Serum Albumin (BSA) was mixed with $400 \mu \mathrm{L}$ of methanolicextractindifferent concentrations of TuAuNp of $10 \mu \mathrm{L}, 20 \mu \mathrm{L}, 30 \mu \mathrm{L}, 40 \mu \mathrm{L}, 50 \mu \mathrm{L}$ respectively, $\mathrm{pH}$ of reaction mixture was adjusted to $6.8 \mathrm{using} 1 \mathrm{~N} \mathrm{Hcl}$ and were incubated at room temperature for $20 \mathrm{~min}$ and heated at $57^{\circ}$ for 20 min in a water bath. Mixture was cooled and absorbance was observed at $660 \mathrm{~nm}$. Control is BSA mixture with $30 \%$ methanol solution. Standard is different concentration of diclofenac sodium. Experiment was repeated thrice.

Percentage inhibition was calculated using the following formula:

$\%$ Inhibition $=($ Absorbance of control-Absorbance of sample $) /$ Absorbance of controlx100

\section{Antibacterial Activity}

The antibacterial activity of Turmeric Au-NPs was evaluated against gram-positive and a gram-negative pathogenic bacterium by Agar-Well diffusion method. The oral pathogenic bacteria under test were three gram positive bacteria such as Streptococci mutans, Staphylococci aureus, Enterococcifaecalis and two gram negative such as Pseudomonasaeruginosa, Klebseilla Pneumoniae. Varying concentrations of Green synthesized AuNPs at 50, $100,150 \mu \mathrm{g} / \mathrm{ml}$ were added to $5 \mathrm{~mm}$ wells and amoxicillin were used as positive control in Muller-hinton agar plates. Plates were incubated at $37^{\circ} \mathrm{C}$ at 24 hours, inference were noted by measuring the diameter of zone of Inhibition in millimeters.

\section{Statistical Analysis}

Data were expressed as Mean value \pm Standard Deviation. Statistical significance between groups was determined by one-way ANOVA analysis using statistical software, SPSS17.0, Pvalue of $>0.05$ were considered as statistically significant.

\section{Results}

\section{Visual Examination and UV-vis Spectroscopy Scanning}

Reduction of $\mathrm{Au} 3+$ into $\mathrm{Au}^{0}$ during exposure to aqueous extract of turmeric was able to be followed by colour change, initial yellow solution to red violet colour within 15 minutes of reaction time, $40^{\circ} \mathrm{C}$. Red violet colourof TuAuNP is due to excitation effect of surface plasmon resonance(SPR) confirming the stability of Au NPs. Fig 1 a. Colloidal and powdered TuAuNp are shown

Figure 1. Colour change in reaction mixture indicating TuAuNP formation (1a), Colloidal and powdered TuAuNp(1b).

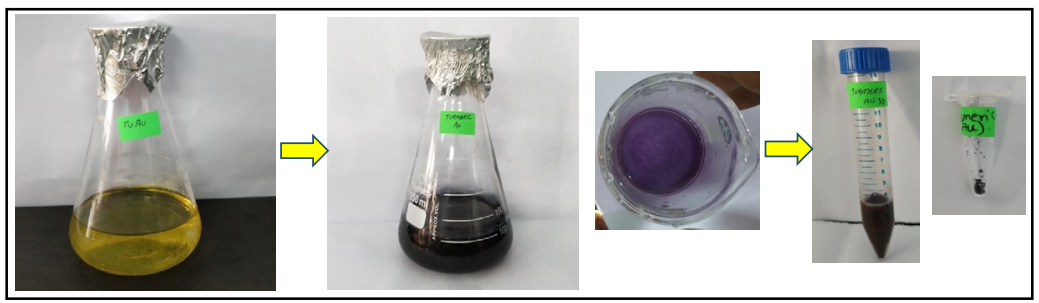

1(a)

1(b)

Figure 2. UV-Vis spectra of TuAuNP obtained by reducing HAucl4 acid with aqueous Turmeric extract.

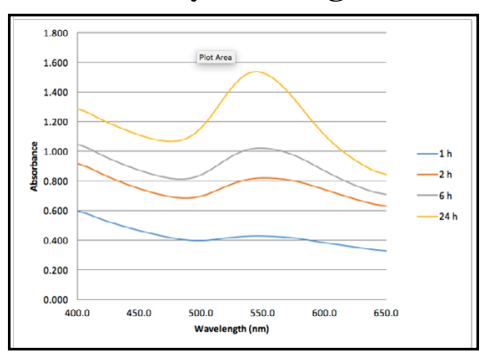


in Fig 1b. Plasmonic property of TuAuNP senable them to be detected by UV-V is spectroscopy measurements. Fig 2 showedultraviolet-visible spectrum of the aqueous medium containing gold nanoparticles with SPR band atan absorption peak at around $540 \mathrm{~nm}$ which preliminarily ascertainedthe synthesis of TuAuNP.

\section{Transmission Electron Microscopy}

TEM analysis revealed biosynthesized gold nanoparticle with size range from 5-15 nm, with average size of $10 \mathrm{nmFig3}$. Morphology were mainly spherical shaped with smooth edges along with oval were found which was well dispersed. Turmeric extract surrounded the well dispersed AuNps served as capping agent.

\section{X-Ray Diffraction Assay}

XRD analysis revealed 4 important intense sharp peaks at $38^{\circ}$, 44॰, $64 \circ$, 77० Fig 4. These diffraction peaks relates tobraggs reflection (111), (200), (210), (310) confirmed the face centered cubic crystal lattice indicating thecrystallinity. These peak match with metallic gold. AuNps average crystalline size were $17.6 \mathrm{~nm}$ calculated by using Debye-Scherrer equation.

Figure 3. Transmission electron microscope(TEM) images of AuNP synthesised from Turmeric extract.

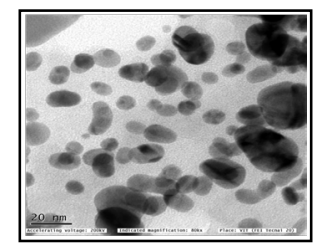

Figure 4. X-ray diffraction pattern of TuAuNPs.

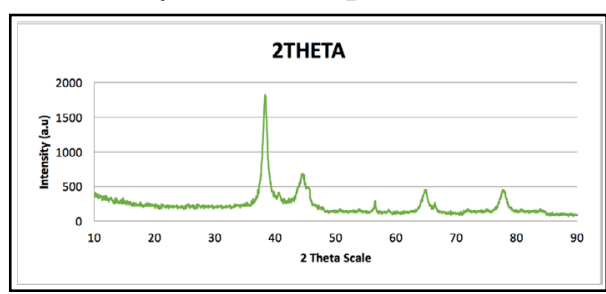

Figure 5. Fourier Transform Infra-red spectroscopy spectrum of TuAuNPs.

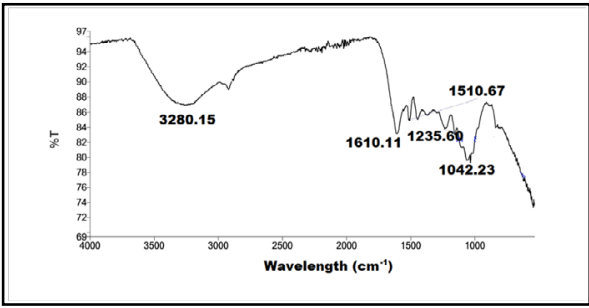

Figure 6. Antioxidant activity of TuAuNps compared with standard: DPPH free radical scavenging activity.

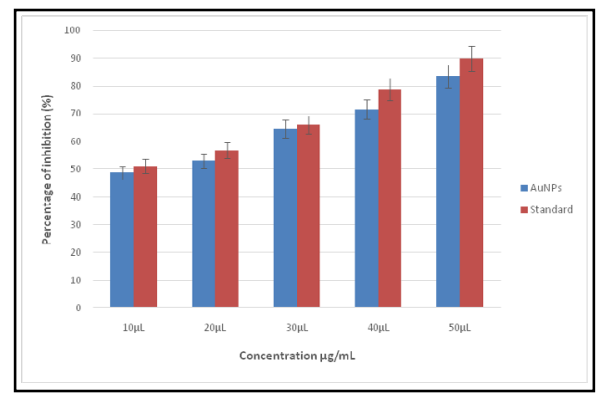

Figure 7. Anti-inflammatory activity of TuAuNPs compared with standard: Bovine serum albumin assay.

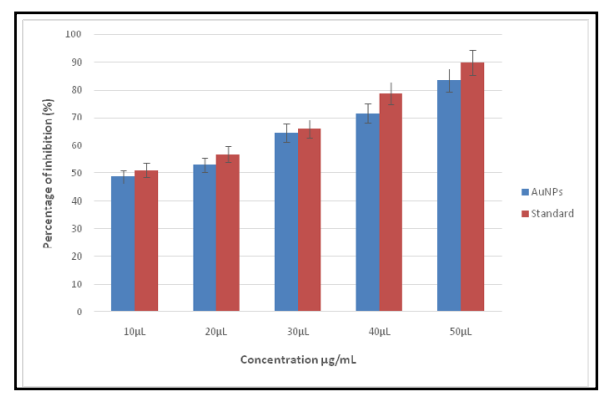


Figure 8a,b,c,d,e. Antibacterial activity of TuAuNp against Enterococcus faecalis(a),Pseudomonas aeruginosa(b),Klebsiella pneumonia(c)e, Streptococcus mutans(d), Staphylococcus aureus(e).

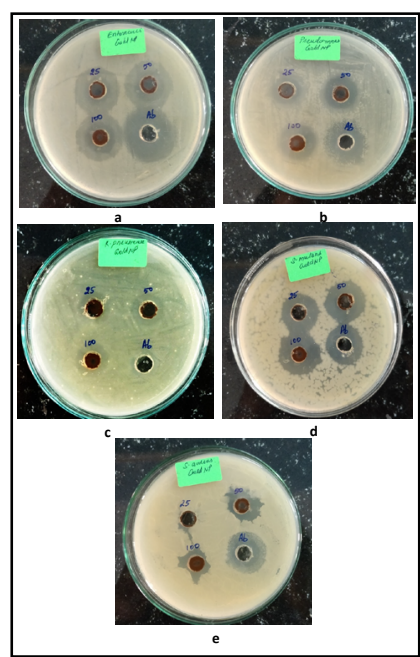

Figure 9. Zone of Inhibition of different concentration of TuAuNps and Standard antibiotics(Amoxycillin) against Oral Pathogens.E.faecalis(a),P.aeruginosa(b),K. pneumonia(c)e, S.mutans(d), S.aureus(e).

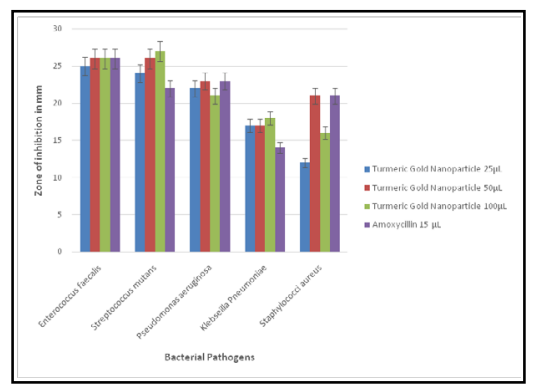

\section{Fourier Transform Infrared Spectroscopy}

FTIR determine the nature of organic constituents of turmeric that reduce $\mathrm{Au} 3+$ and capping biosynthesized nanoparticles. Two bands were observed at $1042.23 \mathrm{~cm}^{-1}$ and $3280.15 \mathrm{~cm}^{-1}$ which were prior and after reduction of $\mathrm{Au} 3+$. Broad bands at $3280.15 \mathrm{~cm}^{-}$ 1 represent $\mathrm{O}-\mathrm{H}$ groups (Carboxylic acid) stretching vibrations forming negative charge around AuNPs providing them stability. Intense peak corresponds to $-\mathrm{C}=\mathrm{C}$ groups stretching vibrations ( $\alpha \beta$ unsaturated ketone), absorption peak at $1235.6 \mathrm{~cm}^{-1}$ represent $\mathrm{C}-\mathrm{N}$ stretching (Amine), $1042.23 \mathrm{~cm}^{-1}$ were $\mathrm{C}-\mathrm{O}$ stretching vibration (Ether). Band intensity shifted from $1610.1 \mathrm{~cm}^{-1}$ to $3280 \mathrm{~cm}^{-1}$ after reduction of Au 3+ by carboxyl groups to form AuNPs. Fig5.

\section{Antioxidant}

DPPH free radical scavenging activity of different concentration of green synthesized AuNP is shown in Fig 6. The antioxidant activity of TuAuNp was done using free radical DPPH. Methanolicviolet coloured DPPH is reduced by hydrogen or electron to yellow or non coloured solution. Antioxidants are biomolecule in plant extract with functional groups on AuNp that reacts with free oxygen radical and reduce DPPH. Biosynthesized AuNP showed $83 \%$ highest inhibitory activity of DPPH radical at highest concentration of $50 \mu \mathrm{g} / \mathrm{ml}$. Dose dependent antioxidant activity were reported which were comparable with DPPH scavenging activity ofascorbic acid (Standard).

\section{Anti-inflammatory}

Different concentration of methanolic TuAuNP extract showed inhibition of protein denaturation Fig 7. TuAuNP showed protein denaturation inhibitory activity of $75.5 \%, 83.4 \%, 83.5 \%$, $88.2 \%, 89.5 \%$ respectively is comparable with synthetic, commercially available anti-inflammatory drug Diclofenac. Highest inhibition and maximum protective activity of TuAuNP was $89.5 \%$ at concentration of $50 \mu \mathrm{g} / \mathrm{mL}$. When concentration of extract increased, there was rise in anti-inflammatory activity which was comparable with standard.

\section{Antibacterial}

Antibacterial activity of TuAuNps from turmeric extracts were tested against five oral pathogens three gram positive, two gram negative bacteria using agar well diffusion method. Wells of $5 \mathrm{~mm}$ were loaded with different concentrations $50 \mu \mathrm{g} / \mathrm{mL}, 100 \mu \mathrm{g} /$ $\mathrm{mL}, 150 \mu \mathrm{g} / \mathrm{mL}$ of AuNPs. Synthetic antibiotic such as Amoxicillin served as control. TuAuNP had good antibacterial activity against Enterococcifaecalis, Pseudomonas aeruginosa, Klebsiella pneumoniae, Streptococcus mutans, moderate antibacterial activity against Staphylococci aureus. (Fig 8a,b,c,d,e). Maximum antibacterial activity of Streptococcus mutanshad zone of inhibition of $27 \mathrm{~mm}$, Klebsiellapneumoniae of $18 \mathrm{~mm}$ at $100 \mu \mathrm{g} / \mathrm{mL}$ which were higher compared to control. Maximum zone of Inhibition in Enterococcusfaecalis is $26 \mathrm{~mm}$, followed by Pseudomonsaaeruginosas is $23 \mathrm{~mm}$, Staphylococci aureusis $21 \mathrm{~mm}$ at $50 \mu \mathrm{g} / \mathrm{ml}$ of TuAuNps which were similar to control. Overall, antibacterial activity of TuAuNP against 3 bacteriawere similar to Antibiotic 
at lesser concentration. In the other 2 bacteria the activity was more than antibiotics at higher concentration. Fig9 Bar graph showed Zone of Inhibition of TuAuNps and control as standard antibiotics amoxicillin against E. faecalis(a), P.aeuruginosa(b), K. pneumoniae(c), S. mutans(d), S. aureus(e).

\section{Discussion}

Oral mucositisis inflammation, ulceration of oropharyngealmucosa that increases morbidity of patient. Natural products with free radical scavenging, antioxidant, antimicrobial, anti-inflammatory, wound healing properties can prevent Chemoradiotherapy induced oral mucositis.

Herbal plants have various phytochemicals that efficiently can biosynthesize nanoparticles that are stable, nontoxic, provides natural capping agent [20]. Rhizome of Curcuma longa $L$ is turmeric, has beneficial medicinal properties that contains phytochemicals like phenolic compounds such as curcumin, proteins, flavonoids, terpinoids [21]. Among inorganic nanometals, gold have attractive material properties with superior functional characteristics [22].

Nanoparticles prepared from plant extract go through 3 phases. Activationphase, Growth phase and termination Phase. In 1stphase, phytochemicals (-OH group) reduce metalion from salt precursor followed by nucleation of metal atoms, 2nd phase leads to addition of synthesized nanoparticle making them structurally strong, in 3rd phase leads to formation of consistent size and shape of AuNp with maximum activity [23]. Optical properties of nanoparticle are unique and exhibit different colours during synthesis. Turmeric extracts with several phytochemicals reacted with $\mathrm{HAuCl}_{4}$ and are converted into TuAUNPs when Au3+ was reduced to $\mathrm{Au} 0$ primarily indicated by colour change to Red violet in reaction mixture within 15 minutes with 24 hours of incubation time. Phytochemicals that forms AuNps act as reducing, Stabilising, Capping agent. Fucoidanassisted AuNP showed colour change from light yellow to pinkish brown with in 15 min which was similar to our study [24]. Colour change from light yellow to wine red was confirmed after 30 min upto 24 hour of incubation at room temperature is observed in Chaetomiumglobosum extract mediated gold nanoparticle [25]. Colour change from colourless to purple red colour within $5 \mathrm{~min}$, as the incubation time increased, colour intensity also increased due to higher synthesis of AuNPs that finally turned to dark purple red colour within 24h [26]. UV -vis spectroscopy is a technique that ascertain the formation of metal nanoparticles in aqueous solutions. Maximum absorption bands were observed at $534 \mathrm{~nm}$ for Clerodendruminume AuNPs [27], SPR peak in the range of 525-555 $\mathrm{nm}$ are seen in spherical shaped AuNPs which are mainly due to purity and small-size of AuNPs [28], was in consistent with our study, TuAuNP showed absorption peak at $540 \mathrm{~nm}$, which was due to surface plasmon resonance.

Morphology, particle size was characterized by TEM. Particles are different shapedat $1 \mathrm{mM}$ of HAucl4 which were triangular, spherical and polyhedronandat $0.5 \mathrm{mM}$ were monodispersed, spherical. They were $15 \pm 10 \mathrm{nmin}$ size with UV-visible spectrum from 540550nm [29]. Similarly, our study showed mostly spherical shaped along with oval, particle size of $5-15 \mathrm{~nm}$. In contrast, $12-29 \mathrm{~nm}$ was the size of synthesized AuNPs and were predominantly round, triangle and irregular in shape [26].
Crystalline structures of AuNpare examined by X-ray diffraction. $2 \theta$ values of three diffraction peaks are $38.3^{\circ}, 64.2^{\circ}$, and $77.3^{\circ}$ were indexed with the planes (111), (220), and (311) that reveals face centre cubic structure of Acanthophoraspicifera bioengineered AuNPs [30]. Additional peaks confirm various other crystalline structures of bioorganic molecules of plant extract which were similar to our study which had diffraction peaks of $38^{\circ}, 44^{\circ}$, $64 \circ, 77 \circ$. The characteristic peak showed that the synthesized AuNps had crystallinity. Average crystalline size for TuAuNp were $17.6 \mathrm{~nm}$,where as the average crystallite size were $13.3 \mathrm{~nm}$ for Au NPs synthesised using Amorphophallus paeoniifolius [31].

FTIR determine the nature of organic constituents of turmeric that reduce $\mathrm{Au} 3+$ and capping biosynthesized nanoparticles. Two bands were observed at $1042.23 \mathrm{~cm}^{-1}$ and $3280.15 \mathrm{~cm}^{-1}$ which were prior and after reduction of Au 3+. Broad bands at $3280.15 \mathrm{~cm}^{-1}$ represent $\mathrm{O}-\mathrm{H}$ groups (Carboxylic acid) stretching vibrations forming negative charge around AuNPs providing them stability. Intense peak corresponds to $-\mathrm{C}=\mathrm{C}$ groups stretching vibrations ( $\alpha$ unsaturated ketone), absorption peak at $1235.6 \mathrm{~cm}^{-1}$ represent $\mathrm{C}-\mathrm{N}$ stretching(Amine), $1042.23 \mathrm{~cm}^{-1}$ were $\mathrm{C}-\mathrm{O}$ stretching vibration (Ether). Band intensity shifted from $1610.1 \mathrm{~cm}^{-1}$ to $3280 \mathrm{~cm}^{-1}$ after reduction of $\mathrm{Au} 3+$ by carboxyl groups to form AuNPs.

FTIR spectroscopy analysis shows various bond between plant extract and AuNPs, revealed active constituents and functional groups that has the role of reduction, capping and stabilising agents. In our study, $3280.15 \mathrm{~cm}^{-1}$ represent $\mathrm{O}-\mathrm{H}$ groups (Carboxylic acid), $1610.1 \mathrm{~cm}^{-1}$ corresponds to $-\mathrm{C}=\mathrm{C}$ groups stretching vibrations ( $\alpha \beta$ unsaturated ketone), $1235.6 \mathrm{~cm}^{-1}$ represent $\mathrm{C}-\mathrm{N}$ stretching (Amine), $1042.23 \mathrm{~cm}^{-1}$ were C-O stretching vibration (Ether). Phenols, flavonoids are involved in reduction of metal ions,amines, carboxylic acid play a role in reduction process by donating free electrons to metal ions. Amine, carboxylate are responsible for stabilization of synthesized NPs, binds to NP and prevent agglomeration [32]. In a study by Singh et al., 2018, absorption bands were, 3360 to $3406 \mathrm{~cm}^{-1}$ (OH-stretching), 2915 to $2934 \mathrm{~cm}^{-1}$ (C-H stretching), 1382 to $1384 \mathrm{~cm}^{-1} \mathrm{C}-\mathrm{O}-\mathrm{H}$ bending of carboxylic acids vibrations, 1025 to $1072 \mathrm{~cm}^{-1} \mathrm{C}-\mathrm{O}$ bending vibrations which were almost similar to our studies [33].

Antioxidant capacity were analysed by measuring their abilities to scavenge DPPH free radicals. Ascorbic acid (Standard) had the maximum antioxidant potential. TuAuNPs had good antioxidant potential which were comparable to standard reference. Spherical shaped nanoparticles showed better antioxidant activity up to 45\% where as AuNPs polyhedral in shapebio-synthesized using Acinetobacter SW30 isolate did not show antioxidant properties [32] which were similar to our study, where in the biosynthesized TuAuNP were mostly spherical and showed $83 \%$ highest inhibitory activity of DPPH radical at highest concentration of $50 \mu \mathrm{g} /$ $\mathrm{mL}$. Dose dependent antioxidant activity were reported. Plant extract containing hydroxyl group of phenolic compounds can prevent lipid peroxidation by free radical scavenging and enhance the antioxidant activities [34]. In a study, synthesized Acanthophoraspicifera AuNPs showed the highest antioxidant activity of $62.8 \%$ at $500 \mu \mathrm{g} / \mathrm{mL}$, which was in contrast to our study achieved greater potential at lower dose.Inhibition of $35-96 \%$ at $256 \mathrm{mg} /$ $\mathrm{mL}$ for DPPH activity was similar to our study [26].

Bovine serum albumin was analysed to inhibit protein denatura- 
tion. Highest inhibition of TuAuNP showed $89.5 \%$ compared to control, diclofenac at concentration of $50 \mu \mathrm{g} / \mathrm{mL}$. Increase in phytochemical content leads to more anti-inflammatory activity. Effect was observed at much smaller doses (40 and $80 \mathrm{mg} / \mathrm{kg}$ ) of gold nanoparticles and was similar to diclofenac sodium used as a standard analgesic. Gold nanoparticles conjugated with biomolecules showed unique anti-inflammatory properties by lowering endothelial leukocyte interaction and leukocyte influx to adjacent tissues and marked reduction of chemotaxis [35].

TuAuNP had good antibacterial activity against Enterococci and Streptococcus mutans, Pseudomonas aeruginosa, Klebsiella pneumoniae, moderate antibacterial activity against Staphylococci aureus in comparison to standard drug Amoxycillin $15 \mu \mathrm{g} / \mathrm{mL}$. There is dose dependent antimicrobial activity. Acanthophora spicifera AuNPs exhibited strong antibacterial activity against V. harveyiand S. aureus [30]. In our study, highest zone of inhibition was seen in Streptococcus Mutans of $27 \mathrm{~mm}$ at $100 \mu \mathrm{g} / \mathrm{mL}$, where as the highest zone of inhibition in V. harveyi is $22 \pm 0.3 \mathrm{~mm}$ followed by S. aureusis $18.7 \pm 0.5 \mathrm{~mm}$ at $100 \mu \mathrm{g} / \mathrm{mL}$ [26].

Streptococcus Mutans had lowest zone of inhibition of $24 \mathrm{~mm}$ at $25 \mu \mathrm{g} / \mathrm{mL}, 25 \mathrm{~mm}$ were recorded for Enterococcus at $25 \mu \mathrm{g} / \mathrm{mL}$, zone of inhibition of Staphylococci aureus was $12 \mathrm{~mm}$ at $25 \mu \mathrm{g} /$ $\mathrm{mL}$, Klebsiella Pneumoniae of $17 \mathrm{~mm}$ at $50 \mu \mathrm{g} / \mathrm{mL}$, Pseudomonas aeruginosa showed $21 \mathrm{~mm}$ at $100 \mu \mathrm{g} / \mathrm{mL}$. Zone of Inhibition for Control was $16 \mathrm{~mm}$ for Enterococcifaecalis, $22 \mathrm{~mm}$ for $\mathrm{S}$ mutans, $23 \mathrm{~mm}$ for Pseudomonas, $14 \mathrm{~mm}$ for Klebsiella Pneumoniae, Staphylococciaureus at $21 \mathrm{~mm}$. Bacterial strains were inhibited by P. domestica gum-loaded gold nanoparticles but with smaller zones of inhibition against Gram-positive strain of S. aureus(10.5 $\pm 0.6 \mathrm{~mm})$, Gram negative strains of E. coli $(10 \pm 0.4 \mathrm{~mm})$ andP. aeruginosa $(8.2 \pm 0.3 \mathrm{~mm})$ [36]. Treatment with AuNP changed the shape and size of bacteria due to coating of nanoparticles on surface. They easiliy penetrate the peptidoglycan membrane of S. aureus and P. aeuruginosa causing membrane destruction, expelling the cellular content, leading to cell death [37]. In our study, antibacterial activity was more towards gram positive compared to gram negative bacteria. Streptococcus mutans were more susceptible and staphylococci aureus were most resistant gram positive bacteria. Pseudomonas aeruginosa were more susceptible and Klebsiella Pneumoniae were most resistant gram negative bacteria. Exact mechanism of inhibitory action of TuAuNps on bacteria were not well understood. But several mechanisms of their antibacterial activity were previously reported. Difference in antibacterial activity depends on cell wall structure, as gram positive have thick peptidoglycan layer and gram negative had thin with lipopolysaccharide impermeable to lipophilic substances. TuAuNps form irregular pits on cell wall interact with protein structures S,N,P,O2 cause irreversible damage [26]. Antibacterial activity can cause denaturation of bacterial cell wall, blocking the respiratory function, destroying outer membrane, reduces ATP synthesis of disease causing bacteria [38].

\section{Conclusion}

Present research showed biosynthesis of TuAuNP with bioactive compounds of aqueous turmeric extract through green ecofriendly method. Green synthesized TuAuNPs were characterized by XRD, UV -V is, FTIR, TEM, XRD, FTIR. Results showed green synthesized TuAuNps had good antioxidant, anti-inflammatory and antibacterial activity against oral pathogens when compared to their standards. Phytochemicals increase the biological activities of TuAuNps. Hence this newer turmeric nanoformulation has beneficial propertiesin treating oral mucositis with lesser sideeffects when compared to conventional synthetic drugs.

\section{References}

[1]. Pedersen AM, Forssell H, Grinde B. Orofacial pain conditions-Pain and oral mucosa. pain. 2016;1:3.

[2]. Shaikh S, Kumar SM. Beneficial effects of specific natural substances on oral health. Saudi Med J. 2017 Dec;38(12):1181-1189. PubmedPMID: 29209665.

[3]. Chainani-Wu N. Safety and anti-inflammatory activity of curcumin: a component of tumeric (Curcuma longa). J Altern Complement Med. 2003 Feb;9(1):161-8. PubmedPMID: 12676044.

[4]. Zhang Y, Rauf Khan A, Fu M, Zhai Y, Ji J, Bobrovskaya L, et al. Advances in curcumin-loaded nanopreparations: improving bioavailability and overcoming inherent drawbacks. J Drug Target. 2019 Nov;27(9):917-931. PubmedPMID: 30672353.

[5]. Eckert J, Scott B, Lawrence SM, Ihnat M, Chaaban H. FLLL32, a curcuminanalog, ameliorates intestinal injury in necrotizing enterocolitis. J Inflamm Res. 2017 Jun 14;10:75-81. PubmedPMID: 28652797.

[6]. Anand P, Nair HB, Sung B, Kunnumakkara AB, Yadav VR, Tekmal RR, et al. Design of curcumin-loaded PLGA nanoparticles formulation with enhanced cellular uptake, and increased bioactivity in vitro and superior bioavailability in vivo. BiochemPharmacol. 2010 Feb 1;79(3):330-8. PubmedPMID: 19735646.

[7]. Bhawana, Basniwal RK, Buttar HS, Jain VK, Jain N. Curcumin nanoparticles: preparation, characterization, and antimicrobial study. J Agric Food Chem. 2011 Mar 9;59(5):2056-61. PubmedPMID: 21322563.

[8]. Vairavel M, Devaraj E, Shanmugam R. An eco-friendly synthesis of Enterococcus sp.-mediated gold nanoparticle induces cytotoxicity in human colorectal cancer cells. Environ SciPollut Res Int. 2020 Mar;27(8):8166-8175. PubmedPMID: 31900772 .

[9]. Shankar SS, Rai A, Ahmad A, Sastry M. Rapid synthesis of Au, Ag, and bimetallic Au core-Ag shell nanoparticles using Neem (Azadirachtaindica) leaf broth. J Colloid Interface Sci. 2004 Jul 15;275(2):496-502. PubmedPMID: 15178278.

[10]. Shunmugam R, Balusamy SR, Kumar V, Menon S, Lakshmi T, Perumalsamy H. Biosynthesis of gold nanoparticles using marine microbe (Vibrio alginolyticus) and its anticancer and antioxidant analysis. Journal of King Saud University-Science. 2021 Jan 1;33(1):101260.

[11]. Rajeshkumar S, Malarkodi C, Al Farraj DA, Elshikh MS, Roopan SM. Employing sulphated polysaccharide (fucoidan) as medium for gold nanoparticles preparation and its anticancer study against HepG2 cell lines. Materials Today Communications. 2021 Mar 1;26:101975.

[12]. Mieszawska AJ, Mulder WJ, Fayad ZA, Cormode DP. Multifunctional gold nanoparticles for diagnosis and therapy of disease. Mol Pharm. $2013 \mathrm{Mar}$ 4;10(3):831-47. PubmedPMID: 23360440.

[13]. Zhang Y, Kong N, Zhang Y, Yang W, Yan F. Size-dependent Effects of Gold Nanoparticles on Osteogenic Differentiation of Human Periodontal Ligament Progenitor Cells. Theranostics. 2017 Mar 6;7(5):1214-1224. PubmedPMID: 28435460.

[14]. Jadhav K, Hr R, Deshpande S, Jagwani S, Dhamecha D, Jalalpure S, et al. Phytosynthesis of gold nanoparticles: Characterization, biocompatibility, and evaluation of its osteoinductive potential for application in implant dentistry. Mater SciEng C Mater Biol Appl. 2018 Dec 1;93:664-670. PubmedPMID: 30274099.

[15]. Tijana A, Valentina V, Nataša T, Miloš HM, AtlagićSuzana G, Milica B, et al. Mechanical properties of new denture base material modified with gold \nanoparticles. J Prosthodont Res. 2020 Sep 9. PubmedPMID: 32938880.

[16]. Oyar P, Sana FA, Nasseri B, Durkan R. Effect of green gold nanoparticles synthesized with plant on the flexural strength of heat-polymerized acrylic resin. Niger J ClinPract. 2018 Oct;21(10):1291-1295. PubmedPMID: 30297561.

[17]. Peng C, Gao X, Xu J, Du B, Ning X, Tang S, et al. Targeting orthotopicgliomas with renal-clearable luminescent gold nanoparticles. Nano Res. 2017 Apr;10(4):1366-1376. PubmedPMID: 29034063.

[18]. Essawy MM, El-Sheikh SM, Raslan HS, Ramadan HS, Kang B, Talaat IM, et al. Function of gold nanoparticles in oral cancer beyond drug delivery: Implications in cell apoptosis. Oral Dis. $2020 \mathrm{Jul} 13$.

[19]. Aziz N, Faraz M, Pandey R, Shakir M, Fatma T, Varma A, et al. Facile AlgaeDerived Route to Biogenic Silver Nanoparticles: Synthesis, Antibacterial, and Photocatalytic Properties. Langmuir. 2015 Oct 27;31(42):11605-12. 
PubmedPMID: 26447769.

[20]. Sharma VK, Yngard RA,LinY. Silver nanoparticles: green synthesis and their antimicrobial activities. Adv. Colloid Interface Sci. 2017;145, 1067-1077.

[21]. Alsammarraie FK, Wang W, Zhou P, Mustapha A, Lin M. Green synthesis of silver nanoparticles using turmeric extracts and investigation of their antibacterial activities. Colloids Surf B Biointerfaces. 2018 Nov 1;171:398-405. PubmedPMID: 30071481.

[22]. Kumari S, Panda PK, Pramanik N, Verma SK, Mallick MA. Molecular aspect of phytofabrication of gold nanoparticle from Andrographispeniculataphotosystem II and their in vivo biological effect on embryonic zebrafish (Daniorerio). Environmental Nanotechnology, Monitoring \& Management. 2019 May 1;11:100201.

[23]. Adeyemi JO, Elemike EE, Onwudiwe DC, Singh M. Bio-inspired synthesis and cytotoxic evaluation of silver-gold bimetallic nanoparticles using KeiApple (Dovyaliscaffra) fruits. Inorganic Chemistry Communications. 2019 Nov 1;109:107569.

[24]. Khandanlou R, Murthy V, Wang H. Gold nanoparticle-assisted enhancement in bioactive properties of Australian native plant extracts, Tasmannialanceolata and Backhousiacitriodora. Mater SciEng C Mater Biol Appl. 2020 Jul;112:110922. PubmedPMID: 32409072.

[25]. Ningaraju S, Munawer U, Raghavendra VB, Balaji KS, Melappa G, Brindhadevi $\mathrm{K}$, et al. Chaetomiumglobosum extract mediated gold nanoparticle synthesis and potent anti-inflammatory activity. Anal Biochem. 2021 Jan 1;612:113970. PubmedPMID: 32961250.

[26]. Donga S, Bhadu GR, Chanda S. Antimicrobial, antioxidant and anticancer activities of gold nanoparticles green synthesized using Mangiferaindica seed aqueous extract. Artif Cells NanomedBiotechnol. 2020 Dec;48(1):13151325. PubmedPMID: 33226851

[27]. Khan SA, Shahid S, Lee CS. Green Synthesis of Gold and Silver Nanoparticles Using Leaf Extract of Clerodendruminerme; Characterization, Antimicrobial, and Antioxidant Activities. Biomolecules. 2020 May 29;10(6):835. PubmedPMID: 32486004.

[28]. Balasubramanian S, Kala SM, Pushparaj TL. Biogenic synthesis of gold nanoparticles using Jasminumauriculatum leaf extract and their catalytic, antimicrobial and anticancer activities. Journal of Drug Delivery Science and Technology. 2020 Jun 1;57:101620.

[29]. Nadhe SB, Wadhwani SA, Singh R, Chopade BA. Green Synthesis of AuNPs by Acinetobacter sp. GWRVA25: Optimization, Characterization, and Its Antioxidant Activity. Front Chem. 2020 Jun 18;8:474. PubmedPMID: 32626688 .
[30]. Babu B, Palanisamy S, Vinosha M, Anjali R, Kumar P, Pandi B, et al. Bioengineered gold nanoparticles from marine seaweed Acanthophoraspicifera for pharmaceutical uses: antioxidant, antibacterial, and anticancer activities. Bioprocess Biosyst Eng. 2020 Dec;43(12):2231-2242. PubmedPMID: 32683506.

[31]. Nayem SMA, Sultana N, Haque MA, Miah B, Hasan MM, Islam T, et al. Green Synthesis of Gold and Silver Nanoparticles by Using Amorphophalluspaeoniifolius Tuber Extract and Evaluation of Their Antibacterial Activity. Molecules. 2020 Oct 18;25(20):4773. PubmedPMID: 33080946.

[32]. Wadhwani SA, Shedbalkar UU, Singh R, Vashisth P, Pruthi V, Chopade BA. Kinetics of Synthesis of Gold Nanoparticles by Acinetobacter sp. SW30 Isolated from Environment. Indian J Microbiol. 2016 Dec;56(4):439-444. PubmedPMID: 27784940.

[33]. Singh AK, Srivastava A, Kumar V, Singh K. Phytochemicals, medicinal and food applications of Shatavari (Asparagus racemosus): An updated review. The Natural Products Journal. 2018 Mar 1;8(1):32-44.

[34]. Jalilian F, Chahardoli A, Sadrjavadi K, Fattahi A, Shokoohinia Y. Green synthesized silver nanoparticle from Allium ampeloprasum aqueous extract: Characterization, antioxidant activities, antibacterial and cytotoxicity effects. Advanced Powder Technology. 2020 Mar 1;31(3):1323-32.

[35]. Uchiyama MK, Deda DK, Rodrigues SF, Drewes CC, Bolonheis SM, Kiyohara PK, et al. In vivo and in vitro toxicity and anti-inflammatory properties of gold nanoparticle bioconjugates to the vascular system. Toxicol Sci. 2014 Dec;142(2):497-507. PubmedPMID: 25260831.

[36]. Islam NU, Amin R, Shahid M, Amin M, Zaib S, Iqbal J. A multi-target therapeutic potential of Prunusdomestica gum stabilized nanoparticles exhibited prospective anticancer, antibacterial, urease-inhibition, anti-inflammatory and analgesic properties. BMC Complement Altern Med. 2017 May 23;17(1):276. PubmedPMID: 28535789.

[37]. Amina M, Al Musayeib NM, Alarfaj NA, El-Tohamy MF, Al-Hamoud GA. Antibacterial and Immunomodulatory Potentials of Biosynthesized Ag, Au, Ag-Au Bimetallic Alloy Nanoparticles Using the Asparagus racemosus Root Extract. Nanomaterials (Basel). 2020 Dec 8;10(12):2453. PubmedPMID: 33302432.

[38]. Rajeshkumar S, Malarkodi C, Vanaja M, Gnanajobitha G, Paulkumar K, Kannan C, et al. Antibacterial activity of algae mediated synthesis of gold nanoparticles from Turbinariaconoides. Der PharmaChemica. 2013;5(2):2249. 